\title{
Hausrat- und Privathaftpflichtversicherung
}

Nutzen Sie bereits die Vorteile der FMH Insurance Services-Hausrat- und Privathaftpflichtversicherung? In diesem Rahmenvertrag profitieren Mitglieder von FMH Services von attraktiven Spezialkonditionen. Gerne erstellen wir Ihnen eine kostenlose und unverbindliche Vergleichsofferte zu Ihrer bestehenden Versicherung und zeigen Ihnen Ihr Einsparpotential auf. Prüfen Sie unser Angebot, um umfassend versichert zu sein und Prämien zu sparen!

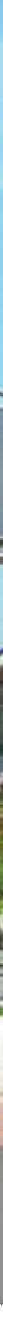

$\square \quad$ Ich möchte eine kostenlose und unverbindliche Offerte der FMH Insurance Services-Praxisversicherung. (Bitte Kopie der aktuellen Versicherungspolice beilegen)

$\square \quad$ Ich wünsche eine persönliche Beratung. Bitte rufen Sie mich an.

Vorname / Name

Adresse

PLZ / Ort

Telefon Privat / Geschäft

Beste Zeit für einen Anruf

E-Mail-Adresse

Antworttalon: bitte einsenden oder per Fax an 0319595010

\section{GMH INSURANCE}

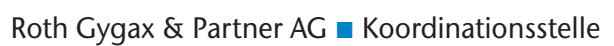

Moosstrasse 2 = 3073 Gümligen

Telefon 0319595000 - Fax 0319595010 mail@fmhinsurance.ch $\square$ www.fmhinsurance.ch 